\title{
COMPARISON OF RESPONSE SPECTRUM ANALYSIS AND CONSTRUCTION SEQUENCE ANALYSIS OF RC AND STEEL- CONCRETE COMPOSITE MULTI-STOREY BUILDING WITH FLOATING COLUMNS
}

\author{
Vignesh Kini $\mathbf{K}^{1}$, Rajeeva $\mathbf{S} \mathbf{V}^{2}$ \\ ${ }^{I}$ PG Student, Department of Civil Engineering, SJB Institute of Technology, Bengaluru, Karnataka, India \\ ${ }^{2}$ Professor, Department of Civil Engineering, SJB Institute of Technology, Bengaluru, Karnataka, India
}

\begin{abstract}
In recent years, many multi-storey and commercial buildings are constructed with architectural complexities. The complexities are soft storeys or floating columns at various positions and storeys. The buildings with floating columns built in seismically active areas are very dangerous. The storey shear that are developed at different storey level in building due to earthquake force is to be transferred to the ground through the shortest path. But due to the presence of floating columns in the structure, there will be discontinuity in the load transfer path which results in the change in the behavior of structure and change of the load transfer path. The building models are analyzed using response spectrum analysis with the assumption that the structure will be subjected to all the loads or full load in a single stretch when the whole structure is constructed completely. The dead load due to various structural components and finishes are imposed on the structure sequentially as the construction is done storey-wise. For better understanding the non-linear behavior of material and the structural members, the construction sequence analysis is carried out. The analysis of the building models is done with the help of CSI ETABS 2016 software. The present study involves the analysis like response spectrum analysis and construction sequence analysis, which is done on a G+20 multi-storey RC and steel-concrete composite building with floating columns at middle of penultimate bay and the parameters like maximum bending moment, maximum shear force and maximum deflection of the transfer beam are compared.
\end{abstract}

Keywords: Floating columns, Regular building, RC structure, Steel-concrete Composite structure, Response Spectrum Analysis, Construction Sequence Analysis, CSI ETABS 2016.

\section{INTRODUCTION}

Today many multi-storey and commercial buildings in India have open storeys as an important feature. This is adopted to utilize the storey for parking, assembly halls and reception lobbies. The total seismic base shear of any building experienced during an earthquake is dependent on its natural period. This seismic shear distribution is dependent on the stiffness of the storeys and seismic mass of storeys along the height of the building.

Based on the overall shape, size, and geometry, along with how the storey shears are transferred to the ground, the building behaves during earthquake. The storey shears at different storeys in a building need to be transferred down to the ground by the shortest path; any discontinuity in the structural members results in the change in the load path. Buildings having vertical setbacks cause a sudden variation in earthquake forces at the levels of discontinuity. The discontinuities in the load path is formed in the buildings with floating columns at an intermediate storeys or ground storey and do not continue upto foundation.

\subsection{Floating Column}

A column is a vertical compression member which starts from foundation level and continues up to roof level which transfers the load to the ground. The word floating column means a vertical member which rests on a beam or transfer girder at its lower level. There are many buildings with floating columns especially above the ground storey which rests on transfer girders so that the open space is available in the first storey. This open space available may be utilized for assembly hall or parking purpose. The transfer girders are to be analyzed, designed, and detailed properly, especially in seismically active zones. The load from the floating column act as a concentrated load on the transfer beam. During the analysis, the column is assumed to be pinned at the base and is therefore taken as a concentrated load on the transfer beam.

\subsection{Composite Structures}

In India, most of the buildings are medium or low rise buildings. Because the construction becomes easy and economical, reinforced concrete members are used widely. Now a day's large number high rise buildings are being constructed. For the construction of high-rise buildings, it 
has been found that the use of composite structural members is more effective and economical than using reinforced concrete members. The practice of steel-concrete composite construction in cities is advantageous over the conventional reinforced concrete construction. Because of less loads in low-rise buildings, reinforced concrete frames are used. But high-rise buildings, due to increased dead load, span restrictions, less stiffness, and drift limitation the conventional reinforced concrete construction cannot be adopted.

\subsection{Linear Dynamic Analysis}

Linear dynamic analysis is also known as response spectrum analysis. In this analysis, the structure is modelled and analyzed as a multi-degree of freedom system with linear elastic stiffness matrix and an equivalent viscous damping matrix. The fundamental natural frequencies and the mode shapes are calculated from the eigen value obtained. Modal transformation then decouples the coupled equations of motion where the principle of orthogonality of the mode shapes with respect to mass, damping and stiffness matrices is applied. The response of each decoupled equation which represents the motion of a single degree of freedom system is obtained using elastic response spectra. Using the appropriate modal combination rules, the peak responses of the significant modes are combined. The response spectrum procedure is accurate when compared to the linear static procedure because higher modes or all the modes are considered in the response spectrum procedure while only the first mode is considered in the equivalent static procedure. But both linear static and linear dynamic procedure are based on linear elastic response.

\subsection{Construction Sequence Analysis}

In general, the structures are analyzed and designed using single step using gravity analysis or seismic analysis on the basic assumption that the structure will be fully loaded at once as shown in the figure-1. But practically, the structure is constructed storey-wise hence dead load is applied storeywise and the finishing loads are also imposed as the structure is constructed in stage wise as shown in the figure1. Gravity analysis or the seismic analysis is carried out in a single step whereas the construction sequence analysis is carried out considering the actual sequential construction of the building as shown in figure-1. To get the sequential effects, each story should be analyzed with its next stories by assigning the vertical loads as stage wise using ETABS. The effects of the sequential or stage-wise construction can be seen and understood once the construction sequential analysis is completed.

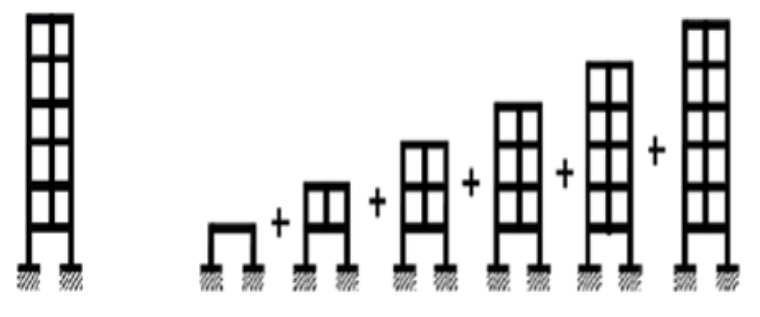

Fig-1: Conventional and construction sequential analysis

\section{LITERATURE REVIEW}

Meghana B.S and T.H. Sadashiva Murthy (2016) [1], reviews on $\mathrm{RC}$ and steel-concrete composite structure with floating column in different positions in plan. Different buildings such as $\mathrm{G}+3, \mathrm{G}+10$ and $\mathrm{G}+15$ storeyed in earthquake zone II and V were analyzed using linear static analysis using ETABS software. Parameters such as storey shear, storey drift and storey displacement were compared with the results of normal RC building.

Jayashri Sarode and Amol S Pote [2], a G+10 RCC beam building and composite transfer beam structure having floating column was analyzed using ETABS. Three models such as normal structure, RCC beam girder structure with floating column, composite beam girder structure with floating column were compared. All the models were analyzed using both static and dynamic seismic method and the parameters such as storey shear, storey drift, storey displacement, time period, maximum nodal displacement and maximum support reaction for all the models were compared for both RC and composite structures.

Meghana B.S and T.H Sadashiva Murthy (2016) [3], here a $\mathrm{RC}$ building structure of $\mathrm{G}+5$ storeys with floating column in exterior position and $\mathrm{RC}$ transfer girder is replaced by composite transfer girder and the analysis of the model is carried out with the help of ETABS software. The analysis involved here are linear static analysis and construction sequence analysis and the parameter such as beam moments and deflection of both the buildings are compared.

Tabassum G Shrihattin and Vanakudre S.B (2015) [4], reviews the effects of linear static analysis and the construction sequential analysis RC and steel-concrete composite buildings. Three-dimensional modeling of RCC and steel-composite 30 storey building situated in zone IV and hard soil type is done and the analysis results are obtained. In both the buildings the frames were assumed as rigid. Finally, the results like shear force, bending moment and storey displacements were compared with both the conventional model and construction sequence model of RCC and steel-composite building respectively using the ETABS-2013 software.

Sri Harsha B and Vikranth J (2014) [5], reviews about the factor which is affecting limit state of serviceability of building that is sequential construction and strength of concrete. Here two cases, linear static analysis for building subjected to whole loading construction sequence analysis 
for the building subjected to sequential loading are considered and deformation in both the cases are compared.

Yousuf Dinar, Munshi Md. Rasel, Muhammad Junaid Absar Chowdhury, Md. Abu Ashraf (2014) [6], reviews about the rigid frame structures of both concrete and steel-concrete composite model of different configurations that have been taken for sequential analysis. The analysis result helps us to understand how the structure respond against loads of construction sequential analysis and linear static analysis. The sequential analysis results were compared with conventional analysis results. The effect of sequential construction and its effect on the overall design of the building has been evaluated using finite element modeling. In this work, multi-storey buildings of 5, 10, 15, 20, 25 and 30 storeys with a floating column in exterior position is considered. The parameters like column axial load and beam maximum moment is compared with both the analysis using ETABS 9.7.2 software.

\subsection{Need for Present Study}

The present literature survey reviews that several works have been done on the behavior of RC and steel-concrete composite structures with and without floating columns to seismic forces. Also, number of studies have been done on the construction sequence analysis on RC and steel-concrete composite structures with floating columns.

a) The literature reviews that the behavior of steelconcrete composite structure with lower steel sections are seen. So, here in the present study the steel-concrete composite structure with higher steel sections are used and the seismic behavior is studied.

b) From the literature review it is seen that work has been done on constructional sequential analysis of buildings along with linear static analysis and not dynamic analysis which includes response spectrum analysis and time history analysis. So, it is required to study the behavior of buildings by analyzing the structure using construction sequence analysis and response spectrum analysis.

\section{OBJECTIVES}

a) To study the response and behavior of a G+20 storeys $\mathrm{RC}$ and steel-concrete composite building with floating columns at middle of penultimate bay situated in Zone IV subjected to seismic forces.

b) To compare the parameters such as maximum bending moment, maximum shear force and maximum deflection of transfer beam in both RC and steelconcrete composite structure with floating columns at middle of penultimate bay.

\section{METHODOLOGY}

The RC and steel-concrete composite multi-storey building with floating columns in the middle of penultimate bay is analyzed using response spectrum analysis and construction sequence analysis with the help of CSI ETABS 2016.
Model-1: G+20 RC multi-storey building with floating columns at the middle of penultimate bay.

Model-2: G+20 steel-concrete composite multi-storey building with floating columns at the middle of penultimate bay.

\section{BUILDING DISCRIPTION}

The structure considered here is a regular building with plan dimension of $30 \mathrm{~m} \times 30 \mathrm{~m}$. In the present study, a G+20 storeys RC structure and steel-concrete composite structure with floating columns at middle of penultimate bay located in seismic Zone IV is considered for the analysis. The height of each storey is $3 \mathrm{~m}$ and the bay spacing in both direction is $5 \mathrm{~m}$.

Table-1: Structural data of RC framed structure

\begin{tabular}{|l|l|}
\hline Dimension of building & $30 \mathrm{~m} \times 30 \mathrm{~m}$ \\
\hline Number of storeys & $\mathrm{G}+20$ \\
\hline Height of each storey & $3.0 \mathrm{~m}$ \\
\hline Dimension of beam & $300 \times 600 \mathrm{~mm}$ \\
\hline Dimension of column & $300 \times 600 \mathrm{~mm}$ \\
\hline Thickness of slab & $150 \mathrm{~mm}$ \\
\hline Thickness of wall & $230 \mathrm{~mm}$ \\
\hline Seismic zone & $\mathrm{IV}$ \\
\hline Zone factor & 0.24 \\
\hline Importance factor & 1.0 \\
\hline Type of soil & Medium \\
\hline Response reduction factor & 5.0 \\
\hline Imposed load & $2.0 \mathrm{kN} / \mathrm{m}^{2}$ \\
\hline Floor finish & $1.5 \mathrm{kN} / \mathrm{m}^{2}$ \\
\hline Roof load & $1.0 \mathrm{kN} / \mathrm{m}^{2}$ \\
\hline Density of masonry wall & $20 \mathrm{kN} / \mathrm{m}^{3}$ \\
\hline Wall load on beams & $12 \mathrm{kN} / \mathrm{m}^{2}$ \\
\hline Grade of concrete & $\mathrm{M} 30$ \\
\hline Grade of steel & Fe 500 \\
\hline
\end{tabular}

Table-2: Structural data of composite framed structure

\begin{tabular}{|l|l|}
\hline Dimension of building & $30 \mathrm{~m}$ x 30m \\
\hline Number of storeys & $\mathrm{G}+20$ \\
\hline Height of each storey & $3.0 \mathrm{~m}$ \\
\hline Dimension of beam & $300 \times 600 \mathrm{~mm}$ with ISMB500 \\
\hline Dimension of column & $300 \times 600 \mathrm{~mm}$ with ISHB450 \\
\hline Thickness of slab & $150 \mathrm{~mm}$ \\
\hline Thickness of wall & $230 \mathrm{~mm}$ \\
\hline Seismic zone & IV \\
\hline Zone factor & 0.24 \\
\hline Importance factor & 1.0 \\
\hline Type of soil & $\mathrm{Medium}$ \\
\hline Response reduction factor & 5.0 \\
\hline Imposed load & $2.0 \mathrm{kN} / \mathrm{m}^{2}$ \\
\hline Floor finish & $1.5 \mathrm{kN} / \mathrm{m}^{2}$ \\
\hline Roof load & $1.0 \mathrm{kN} / \mathrm{m}^{2}$ \\
\hline Density of masonry wall & $20 \mathrm{kN} / \mathrm{m}^{3}$ \\
\hline Wall load on beams & $12 \mathrm{kN} / \mathrm{m}^{2}$ \\
\hline Grade of concrete & $\mathrm{M} 30$ \\
\hline Grade of steel & $\mathrm{Fe} 500$ \\
\hline Grade of structural steel & $\mathrm{Fe} 345$ \\
\hline
\end{tabular}




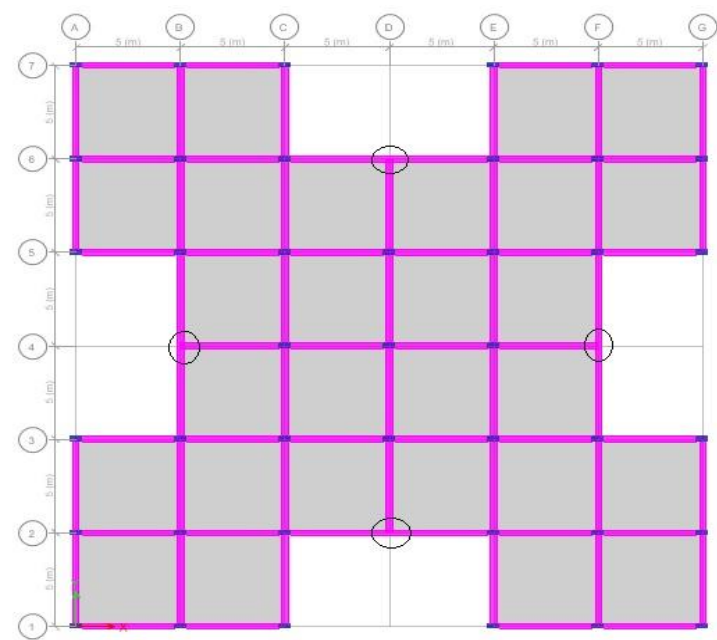

Fig-2: Plan view with floating columns at middle of penultimate bay

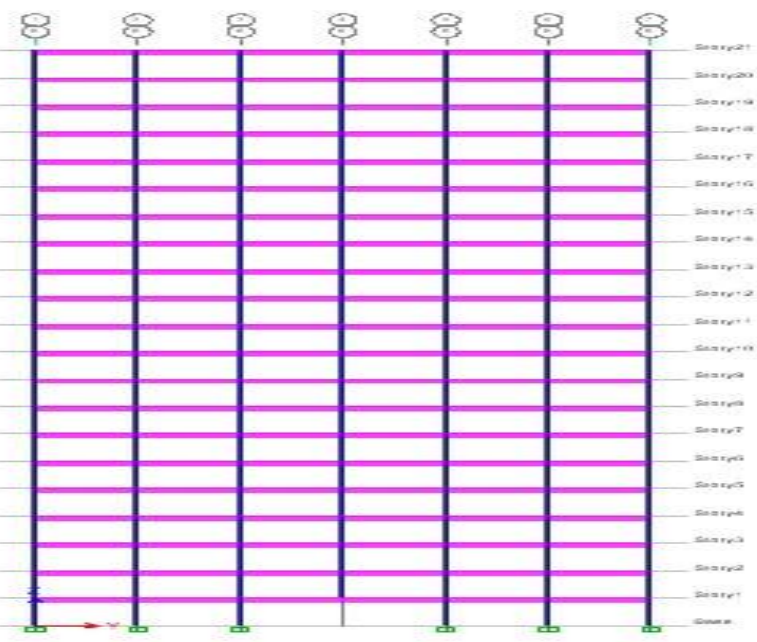

Fig-3: Elevation of G+20 storeys RC and Steel-concrete composite building

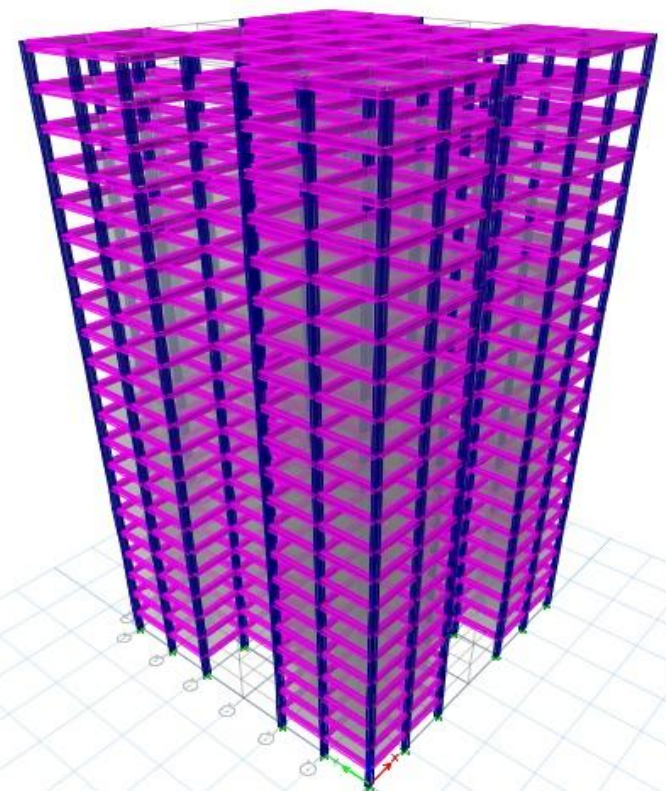

Fig-4: 3D-view

\section{RESULTS AND DISCUSSION}

Table-3: Maximum bending moment of transfer beam

\begin{tabular}{|l|l|l|}
\hline \multirow{2}{*}{$\begin{array}{l}\text { Type } \\
\text { structure }\end{array}$} & \multicolumn{2}{|l|}{ Maximum bending moment $(\mathrm{kNm})$} \\
\cline { 2 - 3 } & $\begin{array}{l}\text { Response } \\
\text { spectrum analysis }\end{array}$ & $\begin{array}{l}\text { Construction } \\
\text { sequence analysis }\end{array}$ \\
\hline RCC & 1054.25 & 1552.17 \\
\hline Composite & 930.78 & 1419.20 \\
\hline
\end{tabular}

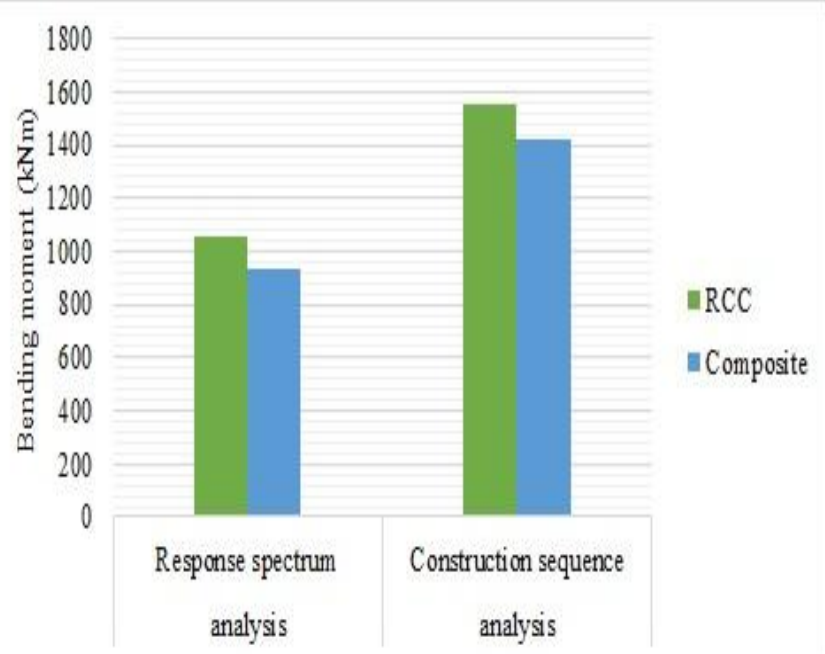

Chart-1: Maximum bending moment of transfer beam

Effect of RC structure and Steel-concrete composite structure on bending moment of transfer beam:

From the table-3and chart-1, the maximum bending moment values obtained for steel-concrete composite transfer beam is decreased by $11.71 \%$ and $8.57 \%$ than reinforced concrete beam for both response spectrum analysis and construction sequence analysis respectively.

Table-4: Maximum shear force of transfer beam

\begin{tabular}{|l|l|l|}
\hline \multirow{2}{*}{$\begin{array}{l}\text { Type of } \\
\text { structure }\end{array}$} & \multicolumn{3}{|l|}{$\begin{array}{l}\text { Maximum shear force }(\mathrm{kN}) \\
\text { analysis }\end{array}$} & $\begin{array}{l}\text { Construction sequence } \\
\text { analysis }\end{array}$ \\
\hline RCC & 522.30 & 742.70 \\
\hline Composite & 480.10 & 699.35 \\
\hline
\end{tabular}

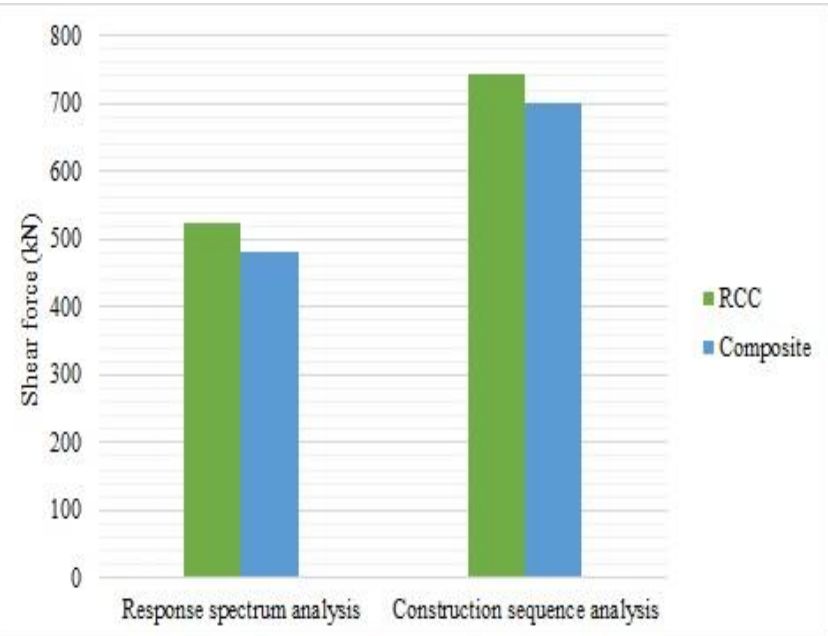

Chart-2: Maximum shear force of transfer beam 
Effect of RC structure and Steel-concrete composite structure on shear force of transfer beam:

From the table-4 and chart-2, the maximum shear values obtained for steel-concrete composite transfer beam is decreased by $8.10 \%$ and $5.84 \%$ respectively than reinforced concrete beam for both response spectrum analysis and construction sequence analysis respectively.

Table-5: Maximum deflection of transfer beam

\begin{tabular}{|l|l|l|}
\hline \multirow{2}{*}{$\begin{array}{l}\text { Type of } \\
\text { structure }\end{array}$} & \multicolumn{2}{|l|}{ Maximum deflection $(\mathrm{mm})$} \\
\cline { 2 - 3 } & $\begin{array}{l}\text { Response spectrum } \\
\text { analysis }\end{array}$ & $\begin{array}{l}\text { Construction } \\
\text { sequence analysis }\end{array}$ \\
\hline RCC & 10.10 & 16.82 \\
\hline Composite & 8.96 & 16.17 \\
\hline
\end{tabular}

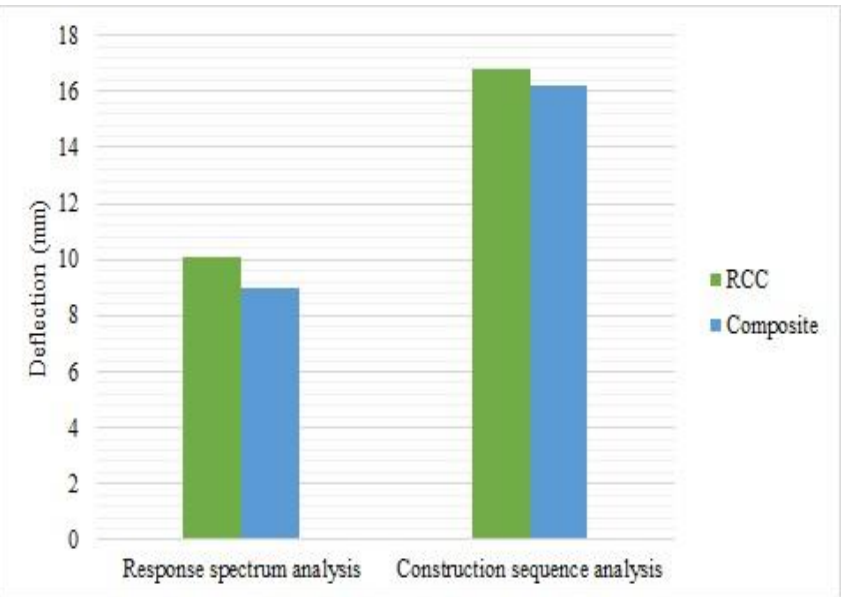

Chart-3: Maximum deflection of transfer beam

Effect of RC structure and Steel-concrete composite structure on shear force of transfer beam:

From the table-5and chart-3, the maximum deflection values obtained for steel-concrete composite transfer beam is decreased by $11.30 \%$ and $3.86 \%$ than reinforced concrete beam for both response spectrum analysis and construction sequence analysis respectively.

\section{CONCLUSION}

a) From the table-3and chart-1, the maximum bending moment values obtained for steel-concrete composite transfer beam is decreased by $11.71 \%$ and $8.57 \%$ than reinforced concrete beam for both response spectrum analysis and construction sequence analysis respectively. From the present study, it is seen that steel-concrete composite transfer beam have more moment carrying capacity than RC transfer beam.

b) From the table-4 and chart-2, the maximum shear values obtained for steel-concrete composite transfer beam is decreased by $8.10 \%$ and $5.84 \%$ respectively than reinforced concrete beam for both response spectrum analysis and construction sequence analysis respectively. Here it is clearly understood that composite beams have less shear force than RC transfer beams.

c) From the table-5and chart-3, the maximum deflection values obtained for steel-concrete composite transfer beam is decreased by $11.30 \%$ and $3.86 \%$ than reinforced concrete beam for both response spectrum analysis and construction sequence analysis respectively. From the analysis and present study, the deflection of steel-concrete composite beams is minimum in both response spectrum and construction sequence analysis.

d) From the present study, it is seen that the steel-concrete composite structure is stiffer than RC structure.

e) The present study reviews that construction sequence analysis should be done to know the forces due to stagewise construction.

\section{ACKNOWLEDGEMENT}

The authors sincerely thank former Professor and Head Prof. Prasad CSMV, Professor and Head Prof. Narendra Kumar H, Department of Civil Engineering, and Dr. Puttaraju, Principal, SJB Institute of Technology, Bengaluru for their encouragement and for providing facilities to carry out this research work as a part of M.Tech project.

\section{REFERENCES}

[1]. Meghana B.S, Sadashiva Murthy T.H, "Effect of floating column on the behavior of composite multistoried building subjected to seismic load", International Research Journal of Engineering and Technology, volume:03, issue:06, June-2016, pp:2613-2619.

[2]. Jayashri Sarode and Amol S Pote, "Analysis of floating column building of composite and RCC beam girder \& comparison with RCC frame structure by using ETABS v9.7.0", August-2016, pp:1464-1469.

[3]. Meghana B.S, Sadashiva Murthy T.H, "Comparison of linear static analysis and construction sequence analysis on multi-storey building with RC floating column resting on RC and composite transfer girders", International Journal of Engineering Trends and Technology, volume: 36, number:07, June-2016, pp:343-346.

[4]. Tabassum G Shirhatti, Vanakudre S.B, "The effects of P-delta and construction sequential analysis of RCC and steel building with respect to linear static analysis", International Research Journal of Engineering and Technology, volume:02, issue:04, July-2015, pp:501-505.

[5]. Sri Harsha B and Vikranth J, "Study and comparison of construction sequence analysis with regular analysis by using ETABS", International Journal of Research Sciences and Advanced Engineering, volume:02, issue:08, OctoberDecember-2014, pp:218-277.

[6]. Yousuf Dinar, Munshi Md. Rasel, Muhammad Junaid Absar Chowdhury, Md. Abu Ashraf, "Chronological construction sequence effects on reinforced concrete and steel buildings", International Journal of Engineering and Science, volume:03, issue:01, December-2014, pp:52-63.

\section{BIOGRAPHIES}

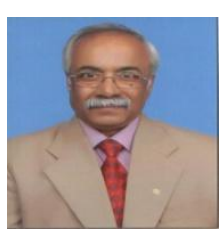

Dr. Rajeeva S V, presently working as a Professor in Department of Civil Engineering, SJBIT, Bengaluru. He has total teaching experience of 33 years. He obtained M.Tech from NITK, Surathkal 
and Ph.D from IIT, Madras with a specialization in

Structural Engineering. He has guided 46 M.Tech and 2

Ph.D thesis. He is a member of ACCE, IIBE, ICI, IE,

ISET, ISTE.

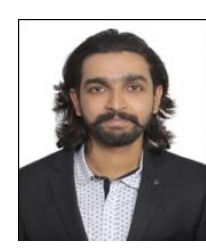

Mr. Vignesh Kini K, PG Student, M.Tech, Structural Engineering, at SJB Institute of Technology, Bengaluru 